UDC 615.038:615.015.1:615.453.2:615.279-021.29

DOI: $10.15587 / 2519-4852.2021 .249880$

\title{
STUDY OF COMPATIBILITY OF COMPONENTS OF A NEW COMBINED DRUG FOR TREATMENT OF ALCOHOLIC INTOXICATION AND ITS HEPATOPROTECTIVE EFFECT ON A MODEL OF ALCOHOLIC LIVER INJURY
}

\author{
Olha Rudakova, Svitlana Gubar, Nataliia Smielova, Dmytro Lytkin, Tatiana Briukhanova, \\ Elena Bezchasnyuk, Nataliia Bevz, Victoriya Georgiyants
}

The aim of the work is the development of a combined drug for use in alcohol intoxication based on the physico-
chemical properties and chemical compatibility of active pharmaceutical ingredients and excipients, and the study
of the hepatoprotective effect in alcoholic hepatitis in rats. Materials and methods. During the studies, physical and physicochemical methods were used, a Specord 200 spectrophotometer (Germany), analytical scales Sartorius (SARTORIUS, Germany), class A volumetric glassware and reagents that meet the requirements of the State Pharmacopoeia of Ukraine (SPhU). Alcoholic hepatitis in rats was reproduced by intragastric administration of an aqueous $40 \%$ ethanol solution at a dose of $7 \mathrm{ml} / \mathrm{kg}$ for 1 week. Results. A new combined agent is proposed for use in alcohol intoxication in the form of an effervescent powder for the preparation of an oral solution, which contains glycine, L-glutamic acid, acetylsalicylic acid, ascorbic acid, fructose/sorbitol and sodium bicarbonate and citric acid to accelerate the dissolution of medicinal substances. To study the compatibility of the components, experimental studies of hygroscopicity, chemical interaction/chemical stability and an assessment of the redox potential of the proposed active pharmaceutical ingredients were carried out. To study the stability of the API, studies were carried out on sugaramine condensation due to the choice of amino acids and ascorbic acid in the composition of drugs. Based on the research results, it was decided to divide the API into 2 packages, separating sodium bicarbonate and glycine, which can interact with ascorbic acid/acetylsalicylic acid and ascorbic acid, respectively. In an in vivo experiment, it was found that the use of the new drug is accompanied by the normalization of the antioxidant-prooxidant status of the liver due to a likely decrease in the $T B A-A P$ level and an increase in the $R G$ index in the liver homogenate relative to the control group.

Conclusions. Evaluation of the physicochemical properties of API allowed us to propose a new combined drug (TS-PP) for use in alcohol intoxication in the form of an effervescent powder for the preparation of oral solution. In alcoholic hepatitis in rats, it was found that the use of the studied drug largely prevents the formation of the effects of the toxic effects of ethanol on the rat organism, which is manifested by inhibition of destruction of hepatocyte membranes, a decrease in the level of LPO products, restoration of the RG index and improvement of the protein synthesizing function of the liver due to the complex effect of amino acids and ascorbic acid contained in the product

Keywords: alcoholic hepatitis, effervescent powder, compatibility, physical and chemical properties, hepatoprotective effect

\footnotetext{
How to cite:

(C) The Author(s) 2021

This is an open access article under the Creative Commons CC BY license hydrate
}

Rudakova, O., Gubar, S., Smielova, N., Lytkin, D., Briukhanova, T., Bezchasnyuk, E., Bevz, N., Georgiyants, V. (2021). Study of compatibility of components of a new combined drug for treatment of alcoholic intoxication and its hepatoprotective effect on a model of alcoholic liver injury. ScienceRise: Pharmaceutical Science, 6 (34), 91-100. doi: http://doi.org/10.15587/2519-4852.2021.249880

\section{Introduction}

According to the World Health Organization, epidemiological data on alcohol abuse worldwide remain disappointing: 3.3 million premature deaths $(5.9 \%$ of total deaths) each year are caused by excessive ethanol consumption. At least 200 different nosologies are formed against the background of alcoholism, the most common of which are liver disease and cancer [1, 2].

Hangover syndrome is one of the most common conditions caused by excessive episodic or regular chronic alcohol consumption [3]. Alcoholic hangover is characterized by a number of symptoms: headache, cognitive and locomotor disorders, dehydration, nausea, emotional lability, liver and gastrointestinal disorders [4]. It should be noted that the high medical and social significance of the hangover syndrome is due not only to the negative impact on human health, but also to the reduction and/or short-term disability, potential danger of driving a car or technical devices, etc. [5]. Based on the above, drugs for the pharmacological correction of hangover syndrome are in demand in the pharmaceutical market. It should be noted that drugs to eliminate the hangover syndrome should be not only a means of symptomatic therapy, but also to comprehensively affect the pathological condition, preventing its burden and the development of complications, especially from the hepatobiliary system [6].

Given the peculiarities of the pharmaceutical market of Ukraine, it should be noted that the range of drugs 
belonging to the OTC segment and targeted for use in alcohol intoxication is quite limited. Most of the drugs on the pharmacy market that are offered to eliminate the symptoms of hangover syndrome are classified as dietary supplements "14.1. Dietary supplements - sorbents" and "14.2. Dietary supplements that help detoxify the body". Among the names registered as a medicinal product, only a few items can be mentioned, which according to the ATC classification belong to the group "A05B A Liver therapy" and to "N07B B Drugs used in alcohol dependence". For the most part, this list is limited to methadoxin, arginine, glutamate, and combination agents containing glycine. Given this, the development and study of new potential correctors of hangover syndrome is one of the promising tasks.

One of the stages in the development of new original drugs is to study the compatibility of components in combined finished dosage forms (FDF). Various physicochemical interactions are possible between the components, which are manifested at the stages of production and storage. Changes in flowability, solubility, appearance of the drug, accumulation of degradation products and interaction of active pharmaceutical ingredients (API) may be observed. Compatibility studies allow to assess the presence or absence of significant interactions between drug components that could reduce the effectiveness and stability of FDF, and to take corrective action at the stage of pharmaceutical development to prevent such interactions.

The aim of the study was to develop a new combined drug for alcohol intoxication based on data on the chemical compatibility of active pharmaceutical ingredients and excipients and its hepatoprotective effect on alcoholic hepatitis in rats.

\section{Research planning (methodology)}

Based on the recommendations of ICH Q8 on a systems approach to pharmaceutical drug development, the compatibility of the API with the excipients listed in 3.2.P.1 of Module 3 of the CTD registration dossier should be assessed. For drugs containing more than one API, the compatibility between the constituent components should also be assessed.

The main stages of the study are:

- justification of the API for introduction to the drug based on symptoms;

- establishing physical, physico-chemical criteria and characteristics of individual substances and their mixtures to assess the compatibility of components;

- research to identify a combination of components that cause deviations in physical and physicochemical criteria; comparative analysis and establishment of the reasons of deviation of criteria of compatibility of components from expected;

- development of recommendations for prevention of problems in the production and storage of drugs related to incompatibility of components.

- pharmacological study of the composition on a standard experimental model of alcoholic liver disease.

\section{Materials and methods}

Substances glycine (p. 2004130449, manufacturer Hebei Huayang Biological Technology Co., Ltd), L-glutamic acid (GA) (p. SLBS0553V, manufacturer Sigma Aldrich), acetylsalicylic acid (ASA) (p. 21787, manufacturer Shandong Xinhua Pharmaceutical Co., Ltd), ascorbic acid (AA) (p. DYD2622000008, manufacturer Northeast Pharmaceutical Group Co., Ltd), fructose (p. 40000174936, manufacturer ADM), sorbitol (p. 19060802, manufacturer Shijiazhuang Ruixue Pharmaceutical Co., Ltd), sodium bicarbonate (p. 01/2020, manufacturer FS Dis Ticaret Limited Sirketi), citric acid (CA) anhydrous (p. 00400159, manufacturer TD Macrochem) were used.

During the experiment were used a Specord 200 spectrophotometer (Germany), Sartorius analytical scales (SARTORIUS, Germany), Class A measuring vessels and reagents that meet the requirements of SPhU.

Physical and physicochemical methods of analysis were used in the research to assess the compatibility of drug components in accordance with the recommendations of the State Pharmacopoeia of Ukraine (SPhU).

\section{Hygroscopicity.}

The hygroscopicity of the APIs and excipients was studied. The determinations were performed in accordance with the requirements of the State Pharmacopoeia of Ukraine (SPhU) of General Article 5.11. "Section "Properties" in monographs.

The chemical compatibility of drug components, the effect of acidic and alkaline media on the API was studied by absorption spectrophotometry in the ultraviolet (UV) region of the spectrum.

Preparation of solutions.

Glycine solution. $0.010 \mathrm{~g}$ of glycine is placed in a $100.0 \mathrm{ml}$ volumetric flask, dissolved in 50 water and adjusted to the mark with the same solvent.

L-glutamic acid solution (GA). $0.010 \mathrm{~g}$ of L-glutamic acid is placed in a $100.0 \mathrm{ml}$ volumetric flask, dissolved in 50 water and adjusted to the mark with the same solvent.

Acetylsalicylic acid solution (ASA). $0.012 \mathrm{~g}$ of acetylsalicylic acid is placed in a $100.0 \mathrm{ml}$ volumetric flask, dissolved in 50 water and made up to the mark with the same solvent (ASA stock solution).

To $1.0 \mathrm{ml}$ of the original ASA solution add $5.0 \mathrm{ml}$ of water.

Ascorbic acid solution (AA). $0.0094 \mathrm{~g}$ of ascorbic acid is placed in a $100.0 \mathrm{ml}$ volumetric flask, dissolved in 50 water and adjusted to the mark with the same solvent (starting solution AA).

To $1.0 \mathrm{ml}$ of the original AA solution add $5.0 \mathrm{ml}$ of water.

Fructose solution. $0.040 \mathrm{~g}$ of fructose is placed in a $100.0 \mathrm{ml}$ volumetric flask, dissolved in $50 \mathrm{ml}$ of water and made up to the mark with the same solvent.

Sorbitol solution. $0.040 \mathrm{~g}$ of sorbitol is placed in a $100.0 \mathrm{ml}$ volumetric flask, dissolved in 50 water and adjusted to the mark with the same solvent. 
To study the possible interaction of two-component solutions with API (ASA and AA): to $1.0 \mathrm{ml}$ of the initial solution of ASA or AA add $5.0 \mathrm{ml}$ of any of these solutions of glycine, GA, fructose or sorbitol.

To determine the possibility of a sugar amine condensation reaction, studies of two-component systems (AA/glycine, $\mathrm{AA} / \mathrm{GA}$ ) at a temperature of $60^{\circ} \mathrm{C}$ for 1 day were done, the result was evaluated visually by color change. Determination of possible oxidation-reduction reactions (redox) among the components of drugs was performed based on analysis of API properties, based on the structure of the molecule and known properties, which are described in the scientific literature.

Pharmacological research.

In vivo studies were performed using a model of alcoholic hepatitis [7] or fatty hepatosis according to other authors [8], which was reproduced by daily intoxication of rats with $40 \%$ aqueous ethanol solution at a dose of $7 \mathrm{ml} / \mathrm{kg}$ for 1 week by intragastric administration [7]. The experiment was performed on 35 outbred male rats weighing 190-210 g. Animals were divided into 5 experimental groups (randomization in groups was performed by minimizing the difference in weight):

- intact control - healthy animals in which the model pathology was not reproduced, receiving solvent (IC);

- control pathology - animals in which reproduced model pathology, receiving solvent $(\mathrm{CP})$;

- test group - animals in which reproduced model pathology, received the test sample (TS-PP);

- reference group 1 - animals in which reproduced model pathology, received a reference sample Glutargin Alkoclean ${ }^{\circledR}($ RS-GA);

- reference group 2 - animals in which reproduced model pathology, received a reference sample Medihronal ${ }^{\circledR}$-Darnitsa (RS-MD).

This research work is regulated by regulatory requirements and is part of a set of preclinical studies required for state registration. The research was conducted in accordance with the methodological recommendations and Orders of the Ministry of Health of Ukraine No. 944 of 14.12.2009 and No. 95 of 16.02.2009 and in compliance with the requirements of Good Laboratory Practice (GLP) $[9,10]$.

The study was conducted in accordance with the Law of Ukraine "On Medicinal Products" and in accordance with the requirements of the SEC of the Ministry of Health of Ukraine on preclinical studies, taking into account the provisions of Directive 2010/63/EU of the European Parliament and of the Council of 22 September 2010 "On the protection of animals used for scientific purposes" [11] (Minutes of the Commission on Bioethics of NUPh No. 5 from 25.03.2021).

Animals were kept in the vivarium NNTLMBD $\mathrm{NUPh}$ in a separate room with controlled microclimate parameters: air temperature $20-24{ }^{\circ} \mathrm{C}$, relative humidity $45-65 \%$, light regime " 12 hours day/night", in polymer cages, 2-3 animals in cages. The animals had free access to water and food ad libitum. Animal care was performed in accordance with generally ac- cepted local and ARRIVE recommendations in accordance with the standard operating procedures of NUPh NNTLMBD [12, 13].

All test samples and solvent were administered intragastrically 1 hour after ethanol solution for 7 days in the following doses (Table 2). 72 hours after the last administration of ethanol, the animals were removed from the experiment by euthanasia in a $\mathrm{CO}_{2}$ box. In the experimental animals, blood was collected for serum, laparotomy was performed, and liver fragments were surgically removed for further homogenization and supernatant.

Glutargin Alkoclean ${ }^{\circledR}$ (LLC "Zdorovya FC", Ukraine, RP No., UA/4022/02/02) and Medichronal®-Darnytsia (PJSC "FC Darnytsia", Ukraine, RP No. UA/6504/01/01, $\mathrm{UA} / 6504 / 01 / 01$ ) were used as reference samples.

Doses of test samples, equivalent to animals, were calculated based on a single therapeutic dose of the drug, taking into account interspecific differences in body weight and body surface area [7, 8]. Since some of the studied drugs are combined and all of them are used to obtain an oral solution, the recalculation of doses was performed by weight of the drug from which the solution was subsequently prepared. As the instructions for use of drugs indicate that in the usual treatment and prevention regime, the minimum daily dose is a single and corresponds to the $1^{\text {st }}$ dosage unit, in both experimental models it was studied. Doses obtained in the calculation process are shown in Table 1.

Table 1

Equivalent to animals' doses of test samples

\begin{tabular}{|c|c|c|}
\hline Studied sample & $\begin{array}{c}\text { Single dose } \\
\text { for an adult }\end{array}$ & $\begin{array}{c}\text { Single dose for an exper- } \\
\text { imental animals (rats) }\end{array}$ \\
\hline TS-PP & $12 \mathrm{~g}$ & $1.24 \mathrm{~g} / \mathrm{kg}$ \\
\hline Glutargin Alkoclean ${ }^{\circledR}$ & $3 \mathrm{~g}$ & $0.31 \mathrm{~g} / \mathrm{kg}$ \\
\hline $\begin{array}{c}\text { Medihron- } \\
\text { al }{ }^{\circledR} \text {-Darnytsia }\end{array}$ & $28.5 \mathrm{~g}$ & $2.95 \mathrm{~g} / \mathrm{kg}$ \\
\hline
\end{tabular}

The test samples were dissolved in the required amount of warm water and administered to animals intragastrically using a special metal enteric probe. The maximum volume of liquid used to dissolve Medichronal ${ }^{\circledR}$-Darnitsa was $200 \mathrm{ml}$ per unit dosage (according to the instructions). The volumes of solutions obtained for administration to animals did not exceed the maximum allowable volume for this route of administration for this species of laboratory animal. To reproduce equal experimental conditions, animals of the group of intact control and control pathology received an equivalent amount of solvent in the same mode $[7,14]$.

Verification of hepatoprotective activity was performed by assessing biochemical parameters. Determination of alanine aminotransferase (ALT) activity in blood serum was performed using a standard set of reagents “BIO-LA-TEST ${ }^{\circledR}$ aminotransferase ALT (ALT 360)" (Erba Lachema sro, Czech Republic), determination of total protein was performed in blood serum was performed using a standard set of reagents "Total protein HP010.01" (Philis- 
it-Diagnostics, Ukraine). Serum studies were performed on a semi-automatic biochemical analyzer MAP-LAB plus ${ }^{\circledR}$ (Biochemical Systems International S.r.l., Italy) according to the relevant instructions.

Reduced glutathione (GSH) in the supernatant of liver tissue homogenate was determined spectrophotometrically by standard methods with Elman's reagent on the optical density of the formed lime color at a wavelength of $412 \mathrm{~nm}$ [8]. The calculation of the content of reduced glutathione was performed according to the formula:

\section{$C=E$ of sample*1094 mg \% (conventional units),}

where $C$ - the concentration of reduced glutathione; $E$ of the sample - the optical density of the test sample.

Determination of TBA-active products (TBA-AP) was performed spectrophotometrically by the standard method of reaction with thiobarbituric acid against a control sample at a wavelength of $532 \mathrm{~nm}$ [15]. The content of TBA reactants in the homogenate is determined by the formula taking into account the homogenization of tissues in the buffer and obtaining the supernatant:

$$
C=\left(E \text { of sample } * 200^{*} 10^{\sigma}\right) /\left(1.56^{*} 10^{5}\right)(\mu \mathrm{mol} / \mathrm{g}),
$$

where $C$ is the concentration of TBA-active products; $E$ of the sample is the optical density of the test sample.

The experimental data were processed using the standard software package "Statistica 6.0" with the calculation of the mean value $(M)$, the standard error of the mean $( \pm m)$ and the confidence interval $(p)$ using analysis of variance by the ANOVA algorithm. Differences between groups were considered statistically significant at $p<0.05$. Verification of samples for normality and comparative a posteriori analysis were performed within the program algorithm [16].

\section{Research results}

The results and conclusions on the hygroscopicity of the API are given in Table 2.

Studies of the chemical compatibility of the components were performed by the method of absorption spectrophotometry in the UV region of the spectrum. To do this, the UV spectra of substances were recorded separately and then in pairs in the same concentration.

The absorption spectra of aqueous solutions of all the proposed components of the drug in the wavelength range from 220 to $320 \mathrm{~nm}$ are shown in Fig. 1

To study the possible interaction of molecules, variants of two-component solutions containing ASA and AA chromophores with other selected components (Fig. 2) and with the addition of $0.5 \%$ sodium bicarbonate solution (Fig. 3, 4) are planned.

Absorbance
The results of experimental studies on the background of modelling alcoholic hepatitis are shown in Tables 3, 4 .

Table 2

Determination of API hygroscopicity

\begin{tabular}{|c|c|c|c|}
\hline No. & API & $\begin{array}{c}\text { The average value } \\
\text { of the increase in } \\
\text { mass, } \%\end{array}$ & Conclusion \\
\hline 1 & Glycine & $0.5 \%$ & $\begin{array}{c}\text { Weakly } \\
\text { hygroscopic }\end{array}$ \\
\hline 2 & GA & $0.07 \%$ & $\begin{array}{l}\text { Non-hygro- } \\
\text { scopic }\end{array}$ \\
\hline 3 & ASA & $1.5 \%$ & $\begin{array}{c}\text { Weakly } \\
\text { hygroscopic }\end{array}$ \\
\hline 4 & AA & $0.02 \%$ & $\begin{array}{l}\text { Non-hygro- } \\
\text { scopic }\end{array}$ \\
\hline 5 & Fructose & $17.9 \%$ & $\begin{array}{l}\text { Blurring s } \\
\text { ubstance }\end{array}$ \\
\hline 6 & Sorbitol & $8.3 \%$ & Hygroscopic \\
\hline 7 & $\begin{array}{l}\text { CA anhy- } \\
\text { drous }\end{array}$ & $5.0 \%$ & Hygroscopic \\
\hline 8 & $\begin{array}{c}\text { Sodium } \\
\text { bicarbonate }\end{array}$ & $0.04 \%$ & $\begin{array}{l}\text { Non-hygro- } \\
\text { scopic }\end{array}$ \\
\hline
\end{tabular}

Table 3

Markers of the functional state of the liver in the serum of rats on the background of the study drugs, $M \pm m(n=7)$

\begin{tabular}{|c|c|c|}
\hline Research group & Total protein, $\mathrm{g} / 1$ & AlAT, mkkat/1 \\
\hline IC & $71.45 \pm 4.28$ & $0.68 \pm 0.09$ \\
\hline CP & $55.50 \pm 3.75^{1}$ & $1.07 \pm 0.14^{1}$ \\
\hline TS-PP & $63.19 \pm 3.50$ & $0.71 \pm 0.08^{2}$ \\
\hline RS-GA & $68.22 \pm 3.86^{2}$ & $0.56 \pm 0.06^{2}$ \\
\hline RS-MD & $60.82 \pm 3.51$ & $0.79 \pm 0.06^{3}$ \\
\hline
\end{tabular}

Notes: ${ }^{1}$-differences are likely for animals of the intact control group $(p<0.05) ;{ }^{2}$ - differences are likely for animals of the control pathology group $(p<0.05) ;{ }^{3}$ - differences are likely for animals of the reference group RS-GA (Glutragin Alkoclean) $(p<0.05) ;{ }^{4}$ - differences are likely for animals of the reference group RS-MD (Medichronal ${ }^{\circledR}$-Darnitsa) $(p<0.05)$

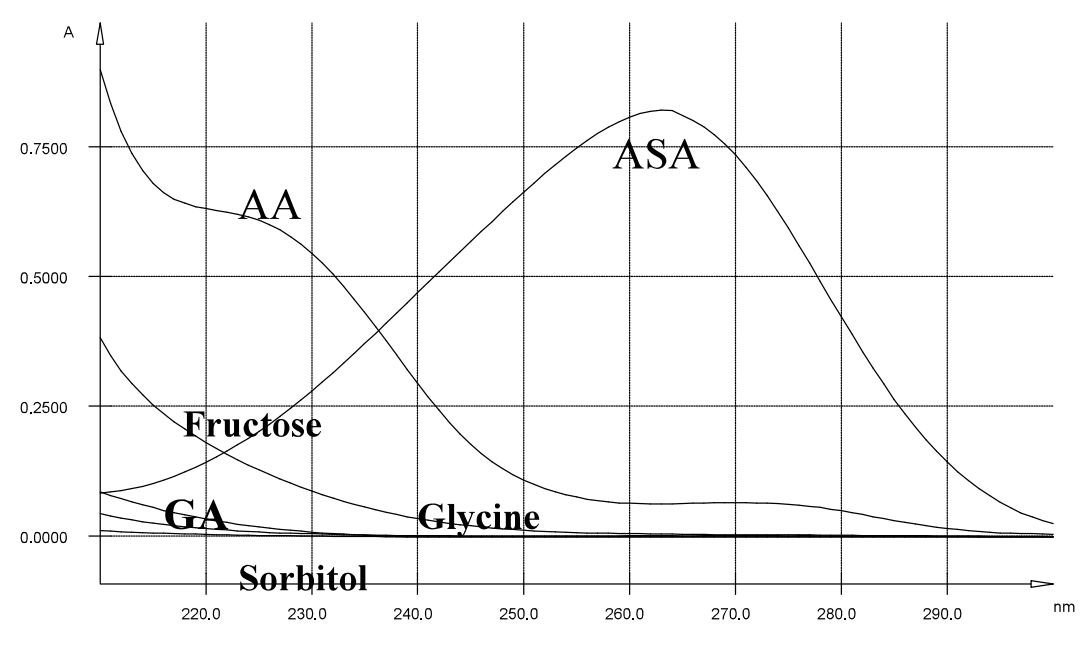

Fig. 1. Absorption of aqueous solutions of drug components in the wavelength range from $210 \mathrm{~nm}$ to $320 \mathrm{~nm}$ 


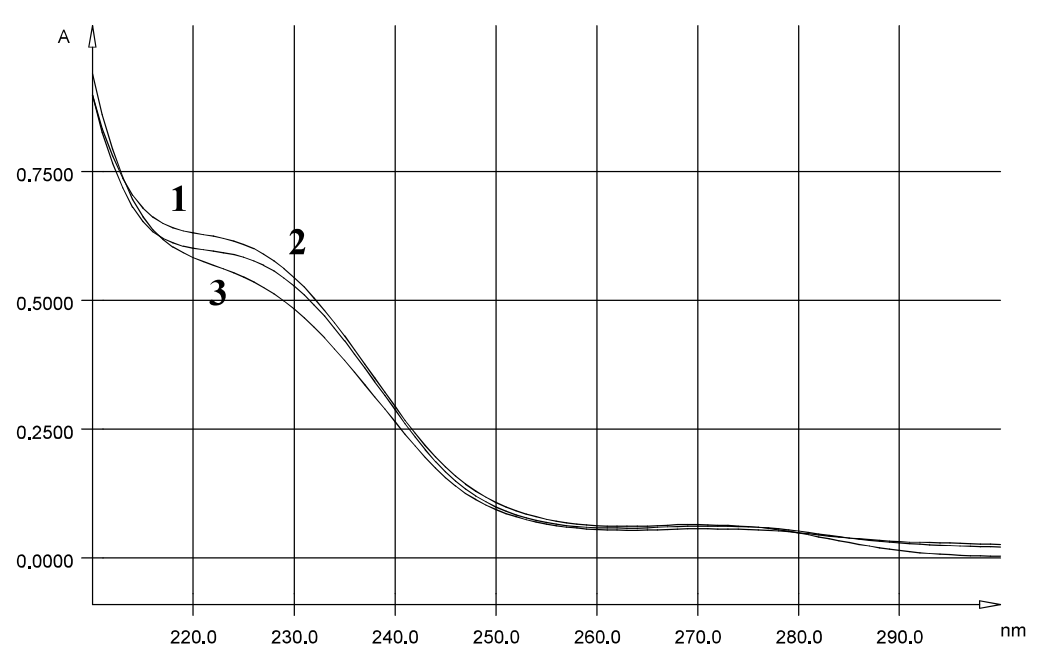

Absorbance

$a$

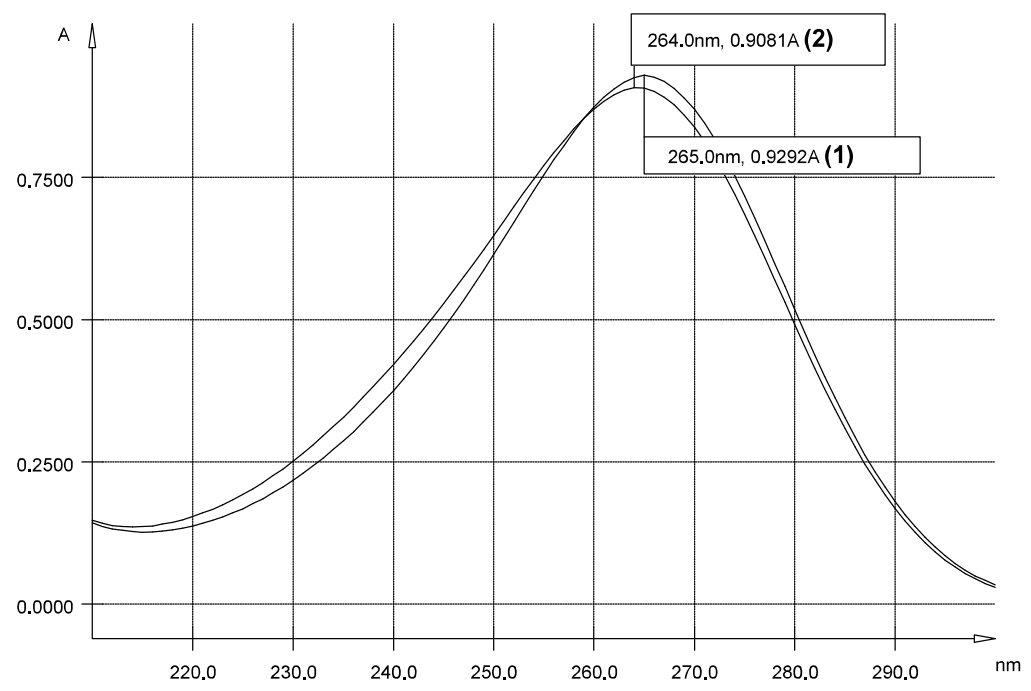

Absorbance

$b$

Fig. 2. UV spectra: $a$ - aqueous solutions of ASA and other components of freshly prepared drugs (1), after 12 hours (2), after 24 hours (3); $b$ - solution of AA and other components of freshly prepared drugs (1) and after 12 hours (2)

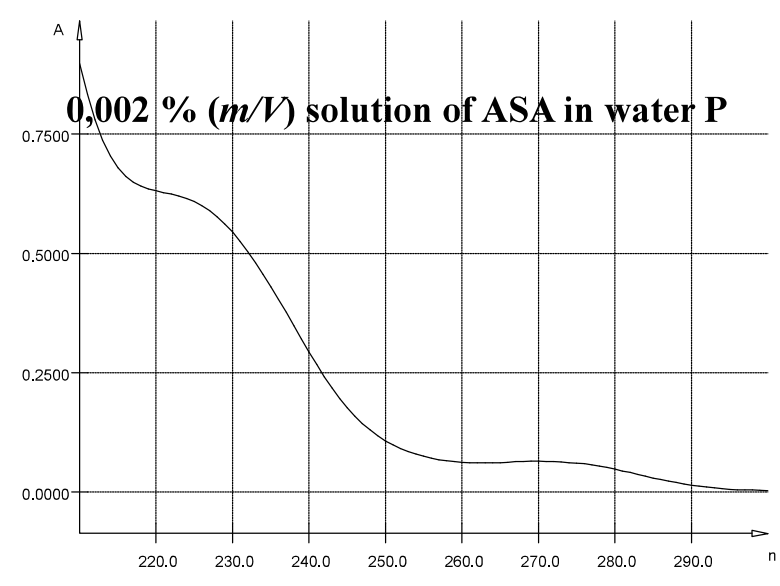
Absorbance

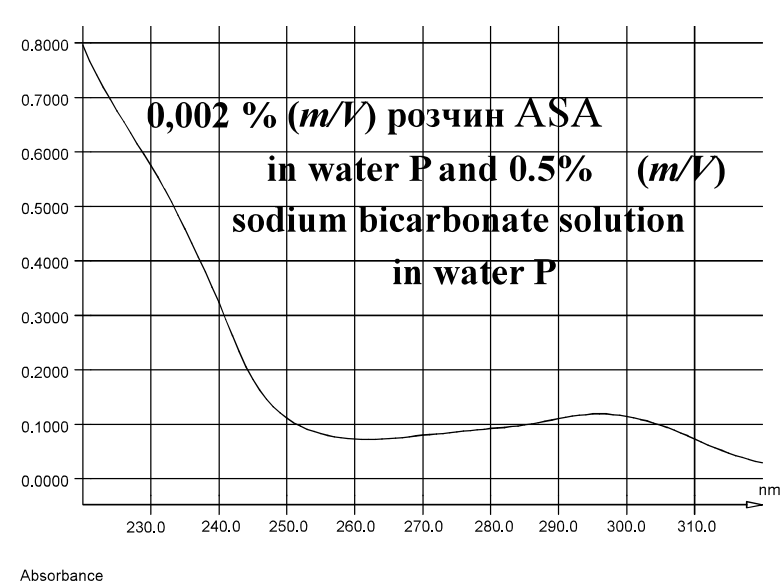

$b$

Fig. 3. UV spectra: $a$ - solution of ASA (0.002\%) in water P; $b$ - solution of ASA $(0.002 \%)$ in water $\mathrm{P}$ and $0.5 \%$ aqueous sodium bicarbonate solution 


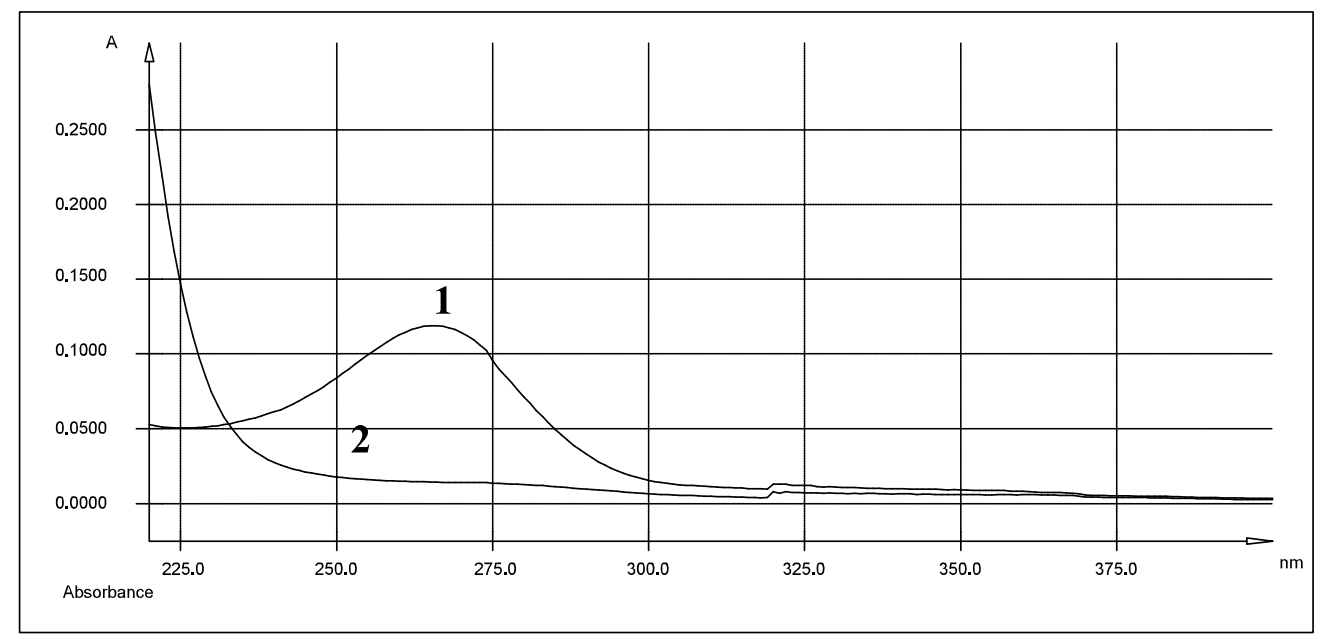

Fig. 4. Absorption spectrum of a solution of ascorbic acid (0.0003\%) in water (1) and in $0.5 \%$ aqueous solution of sodium bicarbonate (2)

Table 4

POL/AOC markers in rat liver homogenate on the background of the study agents, $M \pm m(n=7)$

\begin{tabular}{|c|c|c|}
\hline Research group & GSH, c.u. & TBK-AP, $\mu \mathrm{mol} / \mathrm{g}$ \\
\hline IC & $32.51 \pm 2.02$ & $38.46 \pm 3.15$ \\
\hline CP & $25.16 \pm 1.69^{1}$ & $49.27 \pm 3.21^{1}$ \\
\hline TS-PP & $34.23 \pm 1.47^{2}$ & $36.26 \pm 2.51^{2}$ \\
\hline RS-GA & $31.73 \pm 2.20^{2}$ & $35.71 \pm 1.89^{2}$ \\
\hline RS-MD & $30.94 \pm 1.95^{2}$ & $39.38 \pm 2.53^{2}$ \\
\hline
\end{tabular}

Notes: ${ }^{1}$ - differences are likely for animals of the intact control group $(p<0.05) ;{ }^{2}$ - differences are likely relative to animals of the control pathology group $(p<0.05)$

\section{Discussion of research results}

\section{1. Theoretical substantiation of API}

The composition of the new combined drug (TSPP) for the elimination of alcohol intoxication was theoretically modelled and experimentally substantiated on the basis of obtained data to study the chemical compatibility of API and excipients, respectively, and hepatoprotective effect of the combination.

Against the background of alcohol consumption, the oxidation of substrates used for normal energy metabolism is reduced to adapt to the utilization of ethanol and its metabolic products. After the abolition of alcohol, the brain tissues need time to return to the oxidation of typical energy substrates. Thus, providing easily oxidative energy substrates to the nervous system is one of the effective pharmacocorrection strategies for hangover syndrome [17].

In the liver, the products of amino acid metabolism become substrates for gluconeogenesis, which in turn will provide the brain with glucose [18]. In brain cells, oxidative deamination of glycine and glutamate will restore the pool of pyruvic and $\alpha$-ketoglutaric acid, which will be included in the citric acid cycle to provide the brain with energy. Excess glutamic acid in this tool will help neutralize the ammonia formed in the neurons and, turning into glutamine, enter the liver for further neutralization, so that the activity of citric acid cycle enzymes will not be inhibited, and excess ammonia will not be reversed. acid [19]. Glutamic acid is also a precursor to GABA, which is formed in axons and, upon release, also stimulates the corresponding receptors.

Ethanol metabolism leads to depletion of the pool of reduced cytoplasmic NADP and itramitochondrial NAD [20]. This reduces the amount of reduced glutathione, which can no longer be actively involved in the conversion of DHA to vitamin C, which leads to post-alcohol oxidative stress of brain cells. Thus, depletion of glutathione leads to increased and prolonged hangover. In addition, vitamin $\mathrm{C}$ normally prevents the formation of catechol-protein conjugates from neurotoxic oxidized dopamine, which blocks dopamine receptors and causes post-hangover depression [21]. According to the literature, antioxidants of vitamin origin may affect the severity of the hangover syndrome [22]. To date, the clinical efficacy of ascorbic acid as a monotherapy to eliminate the symptoms of hangover syndrome has not been conclusively proven, but many authors point to the important place of vitamin $\mathrm{C}$ in the pathogenesis of alcohol-related disorders [23, 24]. All this led to the inclusion of glutamic acid as one of the components necessary for the biosynthesis of glutathione, and a natural antioxidant ascorbic acid.

One of the most common symptoms of hangover syndrome is headache, which is associated with direct damaging effects of alcohol metabolism on brain cell membranes, activation of the prostaglandin cascade and proinflammatory interleukins, energy depletion and dehydration of neuroglia, etc. [25]. Acetylsalicylic acid is a common remedy for pain relief on the background of alcohol intoxication, the effectiveness of which has been proven in clinical trials for the treatment of pain episodes of various etiologies and pain in hangover syndrome [26].

On the one hand, the use of acetylsalicylic acid in a combined agent for use in alcohol intoxication could be considered as a factor in deteriorating the safety profile of the drug, as the toxicodynamics of the component targets the liver and stomach, which are most vulnerable to alcohol consumption. On the other hand, the registration of known drugs to eliminate the symptoms of hangover syndrome with acetylsalicylic acid in Ukraine was 
not extended, which led to their disappearance from the range, although such drugs are present in other markets. The lack of alternatives, along with the need to relieve pain, can lead to higher doses of NSAIDs.

Thus, the main APIs for the original composition are glycine, glutamic acid (GA), acetylsalicylic acid (ASA), ascorbic acid (AA). Doses of active substances were selected based on the presence of withdrawal components in analogues that are present or were present in the pharmaceutical market, as well as the criterion for assigning the tool to the OTC segment.

\section{2. Experimental studies of the compatibility} of the components of the composition

A new combined agent for use in alcohol intoxication is offered in the form of effervescent powder for the preparation of oral solution. This dosage form is proposed to accelerate the dissolution of drugs due to the reaction between sodium bicarbonate and citric acid. Carbon dioxide, released when combined with them, enhances the secretory, absorption and motor function of the gastrointestinal tract, increasing the bioavailability of drugs. In the process of studying compatibility, two components of drugs were also considered, as fillers and flavouring agents - fructose and sorbitol.

Experimental studies of hygroscopicity, chemical interaction/chemical stability and redox potential were performed to assess compatibility.

Studies have shown that GA, AA and sodium bicarbonate are non-hygroscopic substances; glycine and ASA are weakly hygroscopic; sorbitol, CA anhydrous are hygroscopic substances, and fructose is a substance that absorbs water well from the air and dissolves in water absorbed from the air. Given the above, it was decided to abandon the use of fructose in the development, as it can reduce the flowability of the components, increase the moisture content in the drug, which will contribute to possible interactions and oxidation processes of the API. At the same time, the properties of sorbitol are more acceptable. In addition, there is a possibility of chemical interaction of fructose with amino acids during Maillard condensation, while sorbitol does not enter into this reaction [27].

The next step was to study the chemical compatibility of components by absorption spectrophotometry in the UV region of the spectrum. To do this, recorded the UV spectrum of substances first separately and then in pairs in the same concentration. The data of Fig. 1 indicate the absence of absorption of glycine, GA, fructose and sorbitol from 220 to $320 \mathrm{~nm}$.

To study the possible interaction of molecules, variants of two-component solutions of substances containing chromophores in the structure, namely ASA and AA, are planned. It was found that the absorption spectra of aqueous solutions of ASA and AA with the addition of other components of the drug do not change. From Fig. 2 it can be concluded that there is no significant effect of drug components on AA and ASA. ASA in aqueous solution gradually decomposes (Fig. 2 a), the addition of solutions of other components of the drug slightly increases this process, but this increase is insignificant.
The risks of API interaction with sodium bicarbonate were assessed by studying the UV spectra taken by adding $0.5 \%$ sodium bicarbonate solution. Given the chemical properties, the most likely effect of alkaline environment on ASA and AA (Fig. 3, 4).

It could be concluded that an alkaline environment has a negative effect on components such as ASA and AA. The possibility of such exposure is manifested in the presence of moisture in the system.

The presence of amino acids in the original composition is the probability of participation of these substances in sugar amine condensation (Maillard reaction). It is known that this reaction is widely used to assess possible interactions between drug components and food [28], as well as in studies of stability and pharmaceutical development $[29,30]$. Since we abandoned fructose as an excipient in favor of sorbitol, the likelihood of amino acids interacting with excipients is impossible. But the composition includes API - ascorbic acid, which under the conditions of the Maillard reaction can interact with amino acids [28].

The results of experimental studies of the behavior of pairs $\mathrm{AA} / \mathrm{GA}$ and $\mathrm{AA} / \mathrm{glycine}$ in the reaction conditions allow us to conclude that there is an interaction of AA with glycine, visual changes in the pair GA/AA were not detected.

The presence of sodium bicarbonate can catalyze the oxidation of AA by oxygen, so their combined presence is also undesirable.

Based on the results of the research, it was decided to divide the API into 2 packages, separating sodium bicarbonate and glycine, which can interact with AA/ASA and AA (package No. 1 - GA 0.500 g; ASA 0.325 g; AA 0.100 g; CA $0.700 \mathrm{~g}$; sorbitol 2,375 g, package No. 2 - glycine $0.300 \mathrm{~g}$, sodium bicarbonate $0.800 \mathrm{~g}$, sorbitol $-2.900 \mathrm{~g}$ ).

\section{3. Experimental pharmacological studies}

Under the conditions of the experiments, the modeling of alcoholic hepatitis was accompanied by hepatocyte lesions, which was confirmed by a probable, relative to intact animals, an increase in serum AlAT activity by $57.4 \%$ (Table 3). This indicated the development on the background of model pathology of cytolytic syndrome caused by damage to hepatocyte membranes. At the same time, the decrease in the functional activity of the liver was evidenced by a significant decrease in the level of total protein in the serum by $22.4 \%$ compared with healthy animals (Table 4). These changes reflected the inhibition of the protein-synthesizing function of hepatocytes, which is consistent with the well-known data on the effects of long-term ethanol intake [30, 31].

The use of TS-PP in the treatment-and-prophylactic regimen was accompanied by normalization of the total protein content and AlAT activity in the serum of animals: the indicators did not differ significantly from those in the IC group ( $p>0.05$ ). Importantly, AlAT activity in animals of this group was significantly reduced by $33.6 \%(p<0.05)$ relative to the CP group, which indicates a decrease in the destruction of hepatocyte membranes under the action of ethanol (Table 3). We associate the 
anti-cytolytic effect of the drug under study with the multifactorial hepatoprotective and antioxidant properties of the amino acids contained in the product. In addition, ascorbic acid, which is part of it, could be involved to support the functioning of the monooxygenase oxidation system - which is key in the disposal of ethanol, thus preventing its damaging effects on liver cells [32, 33]. It is also possible that the drug may have a positive effect on the energy supply of cells, including hepatocytes, due to the content of glutamic acid, which is involved in reamination processes.

The use of the comparison drug Glutargin Alkoclean ${ }^{\circledR}$ was accompanied by a significant normalization of AlAT activity and total serum protein levels $(p>0.05$ vs. CP), while the indicators also did not differ significantly from healthy animals ( $p>0.05$ vs. IC). These dynamics of change, in our opinion, was due to the complex effect of the drug, which was associated with membrane-stabilizing and antioxidant properties of the tool, as well as activating effect on enzyme systems involved in the utilization of ethanol and its toxic metabolites [34].

Under the conditions of our study, the least pronounced effect was observed with the use of Medihronal ${ }^{\circledR}$-Darnitsa: despite the fact that the content of total protein in the serum of animals on the background of its use did not differ significantly from intact rats $(p>0.05)$, AlAT activity under the conditions of therapeutic and prophylactic administration, it probably did not differ from animals of the CP group ( $p>0.05$ vs. CP), but was inferior to efficacy in the RH-HA group $(p<0.05)$ (Table 4). We assume that the data obtained are due to the fact that the hepatoprotective effect of Medichronal ${ }^{\circledR}$-Darnitsa is realized through the conjugation of the main toxic metabolite of alcohol - acetaldehyde (reaction with sodium formate) [35].

One of the key links in the pathogenesis of ethanol toxicity is the activation of free radical oxidation and depletion of antioxidant defense systems, resulting in intensification of peroxidation of lipids (redox), which was confirmed in our experiments by a probable increase in - by $28.1 \%$ and $22.7 \%$, respectively, relative to the IC group ( $p<0.05$, Table 4) [36, 37].

It is important to note that the use of all studied drugs was accompanied by normalization of antioxidant-prooxidant status of the liver, as evidenced by a probable decrease in TBA-AP and increase in GSH in liver homogenate relative to CP $(p<0.05)$ (Table 4$)$. We hypothesize that the realization of the antioxidant properties of the studied TS-PP was associated with the restoration of GSH synthesis, as it contains glutamic acid and glycine - two of the three necessary components for glutathione biosynthesis [38]. In addition, the test sample contains ascorbic acid, which also exhibits antioxidant properties. Reference drugs Glutargin Alkoclean ${ }^{\circledR}$ and
Medihronal®-Darnitsa realized their antioxidant effect, probably also through the restoration of GSH synthesis, as they contain the corresponding amino acids.

Study limitations. Pharmacological studies are limited to the developed composition of the drug.

Prospects for further research. In the future it is planned to develop methods of quality control of active pharmaceutical ingredients of the proposed drug, setting expiration dates and pharmacological study of the drug against the background of key components of the hangover syndrome and study the safety profile.

\section{Conclusions}

Physical, physicochemical criteria and characteristics of components of a new combined drug (TS-PP) for use in alcohol intoxication and their mixtures to assess the compatibility of components have been established.

The combination of drug components that cause deviations according to physical and physicochemical criteria is identified, a comparative analysis is performed and the reasons for deviations of the component's compatibility criteria from the expected ones are established.

Based on the research, recommendations have been developed to prevent problems in the production and storage of drugs associated with incompatibility of components. The composition of TS-PP in the form of effervescent powder for the preparation of oral solution (package No. 1 and package No. 2) is proposed.

To confirm the effectiveness of TS-PP, an experimental model of alcoholic hepatitis in rats was reproduced, accompanied by increased serum alanine aminotransferase activity and impaired liver protein-synthesizing function, activation of free radical oxidation and depletion of antioxidant systems, as evidenced by dynamics.

It was found that the use of TS-PP significantly prevents the formation of the effects of ethanol toxicity on liver function, which is manifested by inhibition of hepatocyte membrane destruction, reduction of redox products, restoration of GSH and improving protein-synthesizing liver function. In our opinion, these effects are related to the complex effect of amino acids and ascorbic acid contained in the product.

The comparison drugs Glutargin Alkoclean ${ }^{\circledR}$ and Medichronal ${ }^{\circledR}$-Darnitsa also normalized these parameters, however, Glutargin Alkoclean ${ }^{\circledR}$ had a more pronounced effect, which was probably due to the peculiarities of pharmacodynamics.

\section{Conflict of interests}

The authors declare that they have no conflicts of interest.

\section{Financing}

The study was conducted with no financial support.

\section{References}

1. Global status report on alcohol and health (2014). Geneva: WHO Press. Available at: https://apps.who.int/iris/bitstream/ 10665/112736/1/9789240692763_eng.pdf

2. Shield, K. D., Parry, C., Rehm, J. (2006). Chronic diseases and conditions related to alcohol use. Alcohol research: current reviews, 35 (2), 155-171. 
3. Jesse, S., Bråthen, G., Ferrara, M., Keindl, M., Ben-Menachem, E., Tanasescu, R. et. al. (2016). Alcohol withdrawal syndrome: mechanisms, manifestations, and management. Acta Neurologica Scandinavica, 135 (1), 4-16. doi: http://doi.org/10.1111/ane.12671

4. Attilia, F., Perciballi, R., Rotondo, C., Capriglione, I., Iannuzzi, S., Attilia, M. L. (2018). Alcohol withdrawal syndrome: diagnostic and therapeutic methods. Rivista di psichiatria, 53 (3), 118-122. doi: http://doi.org/10.1708/2925.29413

5. Verster, J. C., Stephens, R., Penning, R., Rohsenow, D., McGeary, J., Levy, D. et. al. (2010). The Alcohol Hangover Research Group Consensus Statement on Best Practice in Alcohol Hangover Research. Current Drug Abuse Reviewse, 3 (2), 116-126. doi: http://doi.org/10.2174/1874473711003020116

6. Adams, B., Ferguson, K. (2017). Pharmacologic Management of Alcohol Withdrawal Syndrome in Intensive Care Units. AACN Advanced Critical Care, 28 (3), 233-238. doi: http://doi.org/10.4037/aacnacc2017574

7. Stefanova, A. V. (2002). Doklinicheskie issledovaniia lekarstvennykh sredstv. Kyiv: Avitsenna, 528.

8. Mironova, A. N., Buniatian, N. D., Vasileva, A. N. et. al. (Eds.) (2012). Rukovodstvo po provedeniiu doklinicheskikh issledovanii lekarstvennykh sredstv. Part. 1. Moscow: Grif i K, 944.

9. Pro zatverdzhennia Poriadku provedennia doklinichnogo vivchennia likarskikh zasobiv (2009). Nakaz MOZ Ukraini No. 944. 14.12.2009. Available at: https://zakon.rada.gov.ua/laws/show/z0053-10\#Text

10. Likarski zasoby. Nalezhna laboratorna praktyka (2009). Kyiv: Ministerstvo okhorony zdorovia Ukrainy, 27.

11. Directive 2010/63/EU of the European Parliament and of the Council of 22 September 2010 (2010). OJ L 276, 33-79.

12. Kozhemiakin, Yu. M., Khromov, O. S., Filonenko, M. A., Saifetdinova, H. A. (2002). Naukovo-praktychni rekomendatsii z utrymannia laboratornykh tvaryn ta roboty z nymy. Kyiv: Avitsena, 196.

13. Kilkenny, C., Browne, W. J., Cuthill, I. C., Emerson, M., Altman, D. G. (2010). Improving Bioscience Research Reporting: The ARRIVE Guidelines for Reporting Animal Research. PLoS Biology, 8 (6), e1000412. doi: http://doi.org/10.1371/journal.pbio.1000412

14. Nair, A., Jacob, S. (2016). A simple practice guide for dose conversion between animals and human. Journal of Basic and Clinical Pharmacy, 7 (2), 27-31. doi: http://doi.org/10.4103/0976-0105.177703

15. Ellman, G. L. (1959). Tissue sulfhydryl groups. Archives of Biochemistry and Biophysics, 82 (1), 70-77. doi: http://doi.org/ 10.1016/0003-9861(59)90090-6

16. Stalnaia, I. D., Garishvili, T. G. (1977). Metod opredeleniia malonovogo dialdegida s pomoschiu tiobarbiturovoi kisloty. Sovremennye metody v biokhimii, Moscow: Meditsina, 66-68.

17. Khalafian, A. A. (2007). Statistica 6. Statisticheskii analiz dannykh. Moscow: OOO «Binom-Press», 512.

18. Shokri-Kojori, E., Tomasi, D., Wiers, C. E., Wang, G.-J., Volkow, N. D. (2016). Alcohol affects brain functional connectivity and its coupling with behavior: greater effects in male heavy drinkers. Molecular Psychiatry, 22 (8), 1185-1195. doi: http://oi.org/ $10.1038 / \mathrm{mp} .2016 .25$

19. Chourpiliadis, C., Mohiuddin, S. S. (2021). Biochemistry, Gluconeogenesis. Available at: https://www.ncbi.nlm.nih.gov/ books/NBK544346/

20. Ezequiel Leite, L., Nobre, M. J. (2012). The negative effects of alcohol hangover on high-anxiety phenotype rats are influenced by the glutamate receptors of the dorsal midbrain. Neuroscience, 213, 93-105. doi: http://doi.org/10.1016/j.neuroscience.2012.04.009

21. Wilson, D. F., Matschinsky, F. M. (2020). Ethanol metabolism: The good, the bad, and the ugly. Medical Hypotheses, 140, 109638. doi: http://doi.org/10.1016/j.mehy.2020.109638

22. Razvodovsky, Y. (2021). Hangover Syndrome: Pathogenesis and Treatment. International Archives of Substance Abuse and Rehabilitation, 3 (1). doi: http://doi.org/10.23937/2690-263x/1710009

23. Marik, P. E., Liggett, A. (2019). Adding an orange to the banana bag: vitamin C deficiency is common in alcohol use disorders. Critical Care, 23 (1). doi: http://doi.org/10.1186/s13054-019-2435-4

24. Lim, D. J., Sharma, Y., Thompson, C. H. (2018). Vitamin C and alcohol: a call to action. BMJ Nutrition, Prevention \& Health, 1 (1), 17-22. doi: http://doi.org/10.1136/bmjnph-2018-000010

25. Spoelstra-de Man, A. M. E., Elbers, P. W. G., Oudemans-van Straaten, H. M. (2018). Making sense of early high-dose intravenous vitamin C in ischemia/reperfusion injury. Critical Care, 22 (1). doi: http://doi.org/10.1186/s13054-018-1996-y

26. Royle, S., Owen, L., Roberts, D., Marrow, L. (2020). Pain Catastrophising Predicts Alcohol Hangover Severity and Symptoms. Journal of Clinical Medicine, 9 (1), 280. doi: http://doi.org/10.3390/jcm9010280

27. Roze, M., Crucean, D., Diler, G., Rannou, C., Catanéo, C., Jonchère, C. et. al. (2021). Impact of Maltitol and Sorbitol on Technological and Sensory Attributes of Biscuits. Foods, 10 (11), 2545. doi: http://doi.org/10.3390/foods10112545

28. Xiang, J., Liu, F., Wang, B., Chen, L., Liu, W., Tan, S. (2021). A Literature Review on Maillard Reaction Based on Milk Proteins and Carbohydrates in Food and Pharmaceutical Products: Advantages, Disadvantages, and Avoidance Strategies. Foods, 10 (9), 1998. doi: http://doi.org/10.3390/foods 10091998

29. Khoder, M., Gbormoi, H., Ryan, A., Karam, A., Alany, R. (2019). Potential Use of the Maillard Reaction for Pharmaceutical Applications: Gastric and Intestinal Controlled Release Alginate-Albumin Beads. Pharmaceutics, 11 (2), 83. doi: http://doi.org/ 10.3390/pharmaceutics11020083

30. Newton, D. W. (2011). Maillard reactions in pharmaceutical formulations and human health. International Journal of Pharmaceutical Compounding, 15 (1), 32-40.

31. Jayawardena, R., Thejani, T., Ranasinghe, P., Fernando, D., Verster, J. C. (2017). Interventions for treatment and/or prevention of alcohol hangover: Systematic review. Human Psychopharmacology: Clinical and Experimental, 32 (5), e2600. doi: http://doi.org/ 10.1002/hup.2600 
32. Dunn, W., Shah, V. H. (2016). Pathogenesis of Alcoholic Liver Disease. Clinics in Liver Disease, 20 (3), 445-456. doi: http://doi.org/10.1016/j.cld.2016.02.004

33. Nagy, L. E., Ding, W.-X., Cresci, G., Saikia, P., Shah, V. H. (2016). Linking Pathogenic Mechanisms of Alcoholic Liver Disease With Clinical Phenotypes. Gastroenterology, 150 (8), 1756-1768. doi: http://doi.org/10.1053/j.gastro.2016.02.035

34. Staudinger, H., Krisch, K., Leonhäuser, S. (1961). Role of ascorbic acid in microsomal electron transport and the possible relationship to hydroxylation reactions. Annals of the New York Academy of Sciences, 92 (1), 195-207. doi: http://doi.org/ 10.1111/j.1749-6632.1961.tb46119.x

35. Defeng, W., Cederbaum, A. I. (2003). Alcohol, oxidative stress, and free radical damage. Alcohol Research \& Health, 27 (4), 277-284.

36. Cederbaum, A. I., Lu, Y., Wu, D. (2009). Role of oxidative stress in alcohol-induced liver injury. Archives of Toxicology, 83 (6), 519-548. doi: http://doi.org/10.1007/s00204-009-0432-0

37. Cederbaum A. I. (2017). Role of Cytochrome P450 and oxidative stress in alcohol-induced liver injury. Reactive Oxygen Species, 4 (11), 303-319. doi: http://doi.org/10.20455/ros.2017.851

38. Hausladen, A., Ruth, G. A. (2017). Glutathione. Antioxidants in higher plants. CRC Press, 1-30. doi: http://doi.org/ $10.1201 / 9781315149899-1$

Received date 04.11.2021

Accepted date 16.12.2021

Published date 30.12.2021

Olha Rudakova, Postgraduate Student, Department of Pharmaceutical Chemistry, National University of Pharmacy, Pushkinska str., 53, Kharkiv, Ukraine, 61002, Lecturer, Cyclic Committee of Pharmaceutical Chemistry and Pharmacognosis, Professional College of National University of Pharmacy, O. Nevskogo str., 18, Kharkiv, Ukraine, 61140

Svitlana Gubar, PhD, Associate Professor, Department of Pharmaceutical Chemistry, National University of Pharmacy, Pushkinska str., 53, Kharkiv, Ukraine, 61002

Nataliia Smielova, PhD, Assistant, Department of Pharmaceutical Chemistry, National University of Pharmacy, Pushkinska str., 53, Kharkiv, Ukraine, 61002

Dmytro Lytkin, PhD, Vice-director, Educational and Scientific Institute of Applied Pharmacy, National University of Pharmacy, Pushkinska str., 53, Kharkiv, Ukraine, 61002

Tatiana Briukhanova, PhD, Assistant, Department of Biochemistry, Kharkiv National Medical University, Nauky ave., 4, Kharkiv, Ukraine, 61022

Elena Bezchasnyuk, PhD, Head of Laboratory, State Research Laboratory for Quality Control of Medicines, National University of Pharmacy, Pushkinska str., 53, Kharkiv, Ukraine, 61002

Nataliia Bevz, PhD, Associate Professor, Department of Pharmaceutical Chemistry, National University of Pharmacy, Pushkinska str., 53, Kharkiv, Ukraine, 61002

Victoriya Georgiyants, Doctor of Pharmaceutical Sciences, Professor, Head of Department, Department of Pharmaceutical Chemistry National University of Pharmacy, Pushkinska str., 53, Kharkiv, Ukraine, 61002

*Corresponding author: Olha Rudakova, e-mail: rudakovaolha@gmail.com 